\title{
COMMENTARY
}

\section{To be, or not to be immunocompetent}

\author{
Hans-Dieter Volk ${ }^{1,2^{*}}$ and Petra Reinke $e^{2,3}$ \\ See related research by Chang et al., http://ccforum.com/content/17/3/R85
}

\begin{abstract}
Several data support the view that impairment of the inflammatory-immune response is a hallmark of severe sepsis and the level and time of recovery to immunocompetence has a major impact on the clinical outcome of ICU patients. Recent studies demonstrate that improvement of anti-tumour immune response by targeting negative regulatory molecules, such as CD25, chronic T-lymphocyte activation antigen 4, and programmed death-1 receptor (PD-1)/PD-1 L, offers a novel opportunity to prevent or even reverse progression of tumour growth in experimental models and patients. Likewise, severe sepsis is associated with enhanced expression of those negative regulatory molecules, suggesting a novel approach to reverse immunoparalysis in sepsis. Consequently, targeting negative molecules in sepsis can reverse immunoparalysis and improve survival in experimental sepsis, as shown by Chang and colleagues in a recent issue of Critical Care. This opens new opportunities to overcome overwhelming downregulation of the adaptive immune response to prevent and/or improve recovery from sepsis.
\end{abstract}

\section{Introduction}

The recent issue of Critical Care includes a report by the group of Hotchkiss on the improved survival of primary and secondary fungal sepsis by targeting the negative co-stimulatory molecules programmed death-1 receptor (PD-1) and chronic T-lymphocyte activation antigen 4 (CTLA-4) in mice [1].

\footnotetext{
* Correspondence: hans-dieter.volk@charite.de

${ }^{1}$ Institute of Medical Immunology, Charité - University Medicine Berlin,

D-13353, Berlin, Germany

${ }^{2}$ Berlin-Brandenburg Center for Regenerative Therapies, Charité - University

Medicine Berlin, D-13353, Berlin, Germany

Full list of author information is available at the end of the article
}

\section{What is the rationale behind and how far we are from treating patients using this approach?}

PD-1 and CTLA-4 are negative co-stimulatory molecules on immune cells. Their ligands are PD-1 L and CD80/86, respectively, which are expressed on activated immune cells but also on many nonimmune tissues. In contrast to positive co-stimulatory molecules (such as the CD80/86 $\leftrightarrow$ CD28 pathway), cross-linking of negative molecules on immune cells, especially $\mathrm{T}$ cells, by their respective ligands suppresses immune cell activation or even induces apoptosis resulting in lymphopenia. Genetically, deficiency of negative regulatory molecules results in severe hyperinflammatory and autoimmune diseases, demonstrating the key function of regulatory pathways for maintaining immunological homeostasis under different challenging conditions [2,3]. In fact, a successful pregnancy is not feasible without activation of those negative regulatory pathways to allow the acceptance (tolerance) of the semi-allogeneic foetus. Similarly, dominance of regulation is the major aim of transplant immunology to induce transplant tolerance and longterm drug-free allograft survival.

Too much of a beautiful thing, however, limits the protective immune responsiveness. First, it was reported that tumours downregulate the adaptive immune response via activating the negative co-stimulatory pathway that helps the tumour to escape from immune surveillance or even to gain growth support by immunologically deactivated stroma. Overexpression of the ligands of negative co-stimulatory molecules, like PD-1 L, by tumour cells or tumour-surrounding stroma cells mediates anergy/tolerance of tumour-specific immune cells, particularly $\mathrm{T}$ cells. Similarly, chronic virus infections such as HIV are associated with deactivated $\mathrm{T}$ cells overexpressing negative regulatory molecules. In addition, regulatory $\mathrm{T}$ cells that control immune responsiveness are using those molecules for executing their regulatory activity.

Targeting negative regulating molecules (CTLA4, PD$1 / \mathrm{PD}-1 \mathrm{~L}, \mathrm{CD} 25)$ is therefore a novel therapeutic option to reverse undesired immune silencing. In fact, biologics 
targeting those negative molecules result in promising data improving anti-tumour immune response and improving outcome in both experimental models and tumour patients $[4,5]$.

There is still a high unmet medical need to improve the outcome of severe sepsis/septic shock from both the medical and the health-economical points of view. All efforts to target hyperinflammation by broad or specific anti-inflammatory drugs failed in phase II/III clinical trials. This concept of anti-inflammatory therapy of sepsis was developed on the basis of the preclinical models of endotoxin-induced septic shock - models that are obviously not predictive for the immunopathology of sepsis in the majority of critically ill patients.

We could show almost 25 years ago that poor outcome of sepsis is associated rather with immune dysfunction in both immunosuppressed and nonimmunosuppressed patients, particularly if sepsis is established for several days $[6,7]$. The severest form of immune dysfunction, socalled immunoparalysis, is defined as diminished monocytic HLA-DR expression of $<30 \%$ (or $<8,000$ molecules/cell by the new Quantibrite method) and ex vivo lipopolysaccharide-induced TNF secretion of $<300 \mathrm{pg} / \mathrm{ml}$. Monocytic dysfunction reflects the failure of the adaptive immune system, particularly of $\mathrm{T}$ cells. Mediators of $\mathrm{T}$ cells (IFNY and granulocyte-mono cyte colony-stimulating factor from T-helper type 1/T-helper type 22 cells were able to restore immunoparalysis both in vitro and in vivo [7]. Moderate post-traumatic/surgical dysfunction predicts risk of infectious complications and sepsis. Adaptive transfer of IFN $\gamma$-secreting $\mathrm{T}$ cells could reverse immune dysfunction following experimental stroke and prevent stroke-associated pneumonia [8]. These and similar preclinical and clinical data from our group and other groups support the concept of immune monitoringguided rebuilding immunocompetence as a new concept of sepsis prevention/treatment [6-9]. This view is further supported by the recent excellent postmortem study of patients who died from sepsis and multiorgan failure demonstrating strong T-cell exhaustion [10].

Data from several groups demonstrated an overexpression of PD-1/PD-1 L as well as CTLA4 on immune tissue but also on some nonimmune tissues in septic animal models and patients [10-12]. Consequently, targeting negative molecules in sepsis can reverse immunoparalysis and improve survival in experimental sepsis as also shown by the group of Hotchkiss and others $[13,14]$. An editorial by Goyert and Silver discusses PD-1 as a new putative target for sepsis treatment [15]. The positive effects of PD-1 targeting in different models strengthen this idea. In this direction, the very recent report by Chang and colleagues in Critical Care nicely demonstrates the beneficial effect of PD-1 targeting in clinically relevant preclinical models of primary and secondary (post-caecal ligation and puncture) candida sepsis [1]. The results are striking and pushing forward the concept of immune reconstitution as a new option.

\section{What might be the next steps?}

Proof-of-concept trials in patients are still missing. The tools are available because different pharmaceutical companies developed them for oncology. However, encouraging big pharma companies to perform any studies in sepsis has been very difficult because of the failed clinical trials in the past. The data are so promising that clinical trials are a must. We can only recommend that enrolled patients are defined very well by applying standardised immune monitoring to stratify patients into those suffering from immunoparalysis - it makes no sense or can even be harmful to push adaptive immunity in immunocompetent patients during the dominant hyperinflammatory phase. Nobody would give insulin without glucose monitoring to prevent useless treatment of normoglycaemic or hypoglycaemic patients.

\section{Abbreviations}

PD-1: Programmed death-1 receptor; CTLA4: Chronic T-lymphocyte activation antigen 4; IFN: Interferon; TNF: tumour necrosis factor.

\section{Competing interests}

The authors declare that they have no competing interests.

\section{Author details}

${ }^{1}$ Institute of Medical Immunology, Charité - University Medicine Berlin, D-13353, Berlin, Germany. ${ }^{2}$ Berlin-Brandenburg Center for Regenerative Therapies, Charité - University Medicine Berlin, D-13353, Berlin, Germany. ${ }^{3}$ Department of Nephrology and Internal Intensive Care, Charité - University Medicine Berlin, D-13353, Berlin, Germany.

\section{Published: 13 Sep 2013}

\section{References}

1. Chang KC, Burnham C-A, Compton SM, Rasche DP, Mazuski R, Macdonough JS, Unsinger J, Korman AJ, Green JG, Hotchkiss RS: Blockade of the negative co-stimulatory molecules PD-1 and CTLA-4 improves survival in primary and secondary fungal sepsis. Crit Care 2013, 17:R85.

2. Waterhouse $P$, Penninger JM, Timms E, Wakeham A, Shahinian A, Lee KP, Thompson CB, Griesser H, Mak TW: Lymphoproliferative disorders with early lethality in mice deficient in CTLA-4. Science 1995, 270:985-988.

3. Nishimura H, Nose M, Hiai H, Minato N, Honjo T: Development of lupuslike autoimmune diseases by disruption of the PD-1 gene encoding an ITIM motif-carrying immunoreceptor. Immunity 1999, 11:141-151.

4. Sheridan C: Cautious optimism surrounds early clinical data for PD-1 blocker. Nat Biotechnol 2012, 30:729-730.

5. Sznol M, Chen L: Antagonist antibodies to PD-1 and B7-H1 (PD-1L) in the treatment of advanced human cancer. Clin Cancer Res 2013, 19:1021-1034.

6. Volk HD, Reinke P, Falck P, Staffer G, v Baehr R: Prognostic parameters for the clinical outcome of septic disease in immunosuppressed patients. Clin Transplant 1989, 3:246-252.

7. Döcke WD, Randow F, Syrbe U, Krausch D, Asadullah K, Reinke P, Volk HD, Kox W: Monocyte deactivation in septic patients: restoration by IFN- $\gamma$ treatment. Nat Med 1997, 3:678-681.

8. Prass K, Meisel C, Höflich C, Braun J, Halle, Wolf H, Ruscher K, Victorov IV, Priller J, Dirnagl U, Volk HD, Meisel A: Stroke-induced immunodeficiency promotes spontaneous bacterial infections and is mediated by 
sympathetic activation reversal by poststroke T helper cell type 1-like immunostimulation. J Exp Med 2003, 5:725-736.

9. Boomer JS, To K, Chang KC, Takasu O, Osborne DF, Walton AH, Bricker TL, Jarman SD 2nd, Kreisel D, Krupnick AS, Srivastava A, Swanson PE, Green JM, Hotchkiss RS: Immunosuppression in patients who die of sepsis and multiple organ failure. JAMA 2011, 306:2594-2605.

10. Inoue S, Bo L, Unsinger J, Chang K, Hotchkiss RS: Dose-dependent effect of anti-CTLA4 on survival in sepsis. Shock 2011, 36:38-44.

11. Huang X, Venet F, Wang YL, Lepape A, Yuan Z, Chen Y, Swan R, Kherouf H, Monneret G, Chung CS, Ayala A: PD-1 expression by macrophages plays a pathologic role in altering microbial clearance and the innate inflammatory response to sepsis. Proc Natl Acad Sci U S A 2009, 106:6303-6308.

12. Monaghan SF, Thakkar RK, Tran ML, Huang X, Cioffi WG, Ayala A, Heffernan DS: Programmed death 1 expression as a marker for immune and physiological dysfunction in the critically ill surgical patient. Shock 2012 38:117-122.

13. Brahmamdam $P$, Inoue $S$, Unsinger J, Chang KC, McDunn JE, Hotchkiss RS: Delayed administration of anti-PD-1 antibody reverses immune dysfunction and improves survival during sepsis. J Leukoc Biol 2010, 88:233-240

14. Guignant $C$, Lepape $A$, Huang $X$, Kherouf $H$, Denis $L$, Poitevin $F$, Malcus $C$, Chéron A, Allaouchiche B, Gueyffier F, Ayala A, Monneret G, Venet F: Programmed death-1 levels correlate with increased mortality, nosocomial infection and immune dysfunction in septic shock patients. Crit Care 2011, 15:R99.

15. Goyert SM, Silver J: Editorial: PD-1, a new target for sepsis treatment: better late than never. J Leuk Biol 2010, 88:225-226.

$10.1186 / \mathrm{cc} 12897$

Cite this article as: Volk and Reinke: To be, or not to be immunocompetent. Critical Care 2013, 17:185 